\title{
Molecular classification of hepatocellular adenomas: impact on clinical practice
}

\author{
Anne-Laure Védie ${ }^{\ddagger 1,2}$, Olivier Sutter ${ }^{\ddagger, 3}$, Marianne Ziol ${ }^{\ddagger, 4,5}$ \& Jean-Charles Naultt, $\neq, 1,2,5$ \\ 'Service d'Hépatologie, Hôpital Jean Verdier, Hôpitaux universitaires Paris-Seine-Saint-Denis, Assistance publique Hôpitaux de Paris, \\ Bondy, France \\ 2Unité mixte de Recherche 1162, Génomique fonctionnelle des Tumeurs solides, Institut National de la Santé et de la Recherche \\ médicale, Paris, France \\ ${ }^{3}$ Service de Radiologie, Hôpital Jean Verdier, Hôpitaux universitaires Paris-Seine-Saint-Denis, Assistance-Publique Hôpitaux de Paris, \\ Bondy, France \\ ${ }^{4}$ Service d'Anatomopathologie, Hôpital Jean Verdier, Hôpitaux universitaires Paris-Seine-Saint-Denis, Assistance-publique Hôpitaux \\ de Paris, Bondy, France \\ ${ }^{5}$ Unité de Formation et de Recherche Santé Médecine et Biologie humaine, Université Paris 13, Communauté d'Universités et \\ Etablissements Sorbonne Paris Cité, Paris, France \\ *Author for correspondence: Tel.: +33 1537251 94; Fax: +33 1537251 92; naultjc@gmail.com \\ $\ddagger$ Authors contributed equally
}

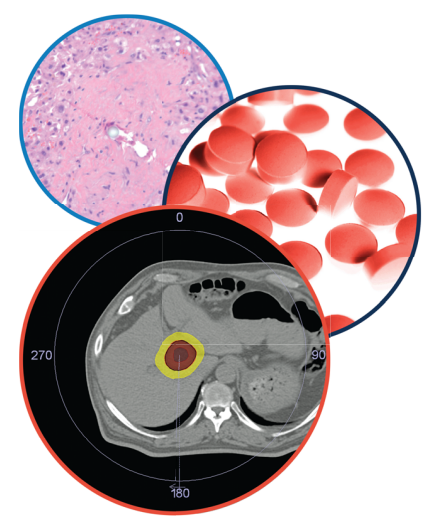

Hepatic Oncology

\section{Practice points}

- Hepatocellular adenoma (HCA) is a benign liver tumor occurring in young women and promoted by oral contraception.

- Malignant transformation and hemorrhage are the main complications of HCA.

- Different molecular subtypes have been described: HNF1A-inactivated HCA, inflammatory HCA, $\beta$-catenin-mutated HCA exon 3, $\beta$-catenin-mutated HCA exon 37 or 8, sonic hedgehog HCA and unclassified HCA.

- Malignant transformation of HCA is more frequent in males and in $\beta$-catenin mutated HCA exon 3.

- Tumor size and sonic hedgehog HCA are risk factors in tumor bleeding.

Hepatocellularadenomas are rare benign liver tumors usually developing in young women using oral contraception. The two main complications are hemorrhage (10-20\%) and malignant transformation into hepatocellular carcinoma $(<5 \%)$. A molecular classification has been recently updated in six major subgroups, linked to risk factors, histology, imaging and clinical features: adenomas inactivated for HNF1A, inflammatory adenomas, $\beta$-catenin-activated adenomas mutated in exon $3, \beta$-catenin-activated adenomas mutated in exon 7-8, sonic hedgehog adenomas, and unclassified adenomas. Indeed, $\beta$-catenin-mutated adenomas in exon 3 are associated with malignant transformation, and sonic hedgehog adenomas with bleeding. This new nosology of hepatocellular adenomas will help to stratify patients according to risk of complications and will guide therapeutics in the future.

First draft submitted: 29 September 2017; Accepted for publication: 20 February 2018; Published online: 09 April 2018

Keywords: $\beta$-catenin $\bullet$ hemorrhage $\bullet$ hepatocellular adenoma $\bullet$ hepatocellular carcinoma $\bullet$ HNF1A $\bullet$ inflammation - malignant transformation • molecular classification • oral contraception • sonic hedgehog

Hepatocellular adenomas (HCAs) are rare benign liver tumors derived from monoclonal proliferation of hepatocytes [1-3]. HCAs are less frequent than other benign liver tumors (liver angiomas, focal nodular hyperplasia [FNH]), with an incidence estimated, in the 1970 s, at around $0.001-0.005 \%$ of women using oral contraception [3,4]. In contrast to HCA, FNH involves polyclonal proliferation of hepatocytes and cannot be considered a tumor per se. HCA develops mainly in young women (median age: 38 years), with a female/male ratio of 8:1 [5]. The principal risk factors are hormonal exposure (estrogens and androgens) and, more rarely, glycogen storage diseases and vascular hepatic disorders [1].

Estrogen exposure is mainly due to long-term use of oral contraception (at least 2 years), but also pregnancy [6]. The association between HCA occurrence and estrogen was identified in the seventies, when women began to

Future Medicine 
widely use estroprogestatives as oral contraception $[1,3,7]$. The incidence of HCA is higher in western than in eastern countries, possibly linked to the less frequent use of oral contraception in Asian populations. Androgen intake for recreative (body building) or therapeutic purposes (Fanconi anemia) has also been associated with development of HCA $[8,9]$. Regression of HCA has been described after estrogen and androgen withdrawal [9,10]. Glycogenesis type IA is an orphan disease defined by a germline-inactivating mutation of glucose- 6 phosphatase. Symptoms are neonatal hypoglycemia and growth delay [11]. Patients with this disease have a high risk of developing multiple HCA during follow-up (almost 50\% at adulthood) [11]. Vascular liver diseases such as Budd-Chiari syndrome, congenital absence of a portal vein, and Fallot tetralogy promote development of malignant liver tumors such as hepatocellular carcinoma (HCC), and benign liver tumors such as focal nodular hyperplasia and HCA [12].

HCA is multiple in $30-40 \%$ of cases, and liver adenomatosis is defined by the presence of 10 or more adenomas $[13,14]$. The two main complications are symptomatic hemorrhage (15-20\%) and malignant transformation into HCC ( $<5 \%$, probably overestimated in surgical series) [15-19]. Differential diagnosis between HCA and very well-differentiated HCC may be difficult, especially in men, even for expert pathologists [19].

A molecular classification of HCA has been proposed based on dysregulation of signaling pathways, due to mutations in oncogenes and tumor suppressor genes occurring in tumor hepatocytes [20]. Five major subgroups have been described: H-HCA defined by inactivating mutations of hepatocyte nuclear factor 1A (HNF1A), inflammatory HCA (IHCA), $\beta$-catenin-mutated HCA exon 3, $\beta$-catenin-mutated HCA exon 7-8, and recently, a new subgroup characterized by activation of sonic hedgehog signaling due to focal deletions that fuse the promoter of INHBE with GLI1 [21,22].

The different subgroups are associated with differing risk factors for HCA, pathological and immunohistochemical features, and risk of complications [20]. This classification could be used in clinical practice to propose preventative action against risk factors in HCA development, in distinguishing HCA from other benign liver tumors, and in determining therapeutic strategies [23].

\section{Molecular classification of HCA \\ HNF1A-inactivated HCA}

HNF1A-inactivated HCA (HHCA) represents $35-45 \%$ of all HCA and is characterized by biallelic inactivating mutations of HNF1A (Table 1) [24].HNF1A encodes a transcription factor involved in hepatocyte differentiation and metabolism control, including lipids (stimulation of aberrant fatty acid synthesis) and glucose (repression of gluconeogenesis, activation of glycolysis) [25,26].

Germline HNF1A mutations were initially described in an autosomal dominant diabetes termed 'maturity onset diabetes of the young, Type 3' (MODY 3) by Yamagata et al. [27]. But, unlike MODY 3 diabetes, where only one allele of HNF1A is inactivated in all cells linked to germline mutations, in HHCA there is a complete inactivation of both alleles in tumor cells [24]. Among all HHCA, 90\% are due to a somatic mutation of both alleles in tumor hepatocytes and $10 \%$ are due to a germline mutation of one allele, with additional somatic inactivated mutation of the other allele, according to the Knudson model of tumor suppressor genes described in retinoblastomas [24,28-29].

Moreover, in HHCA, no additional genetic alterations have been identified; consequently, biallelic-inactivating mutations of HNF1A are exclusive of CTNNB1, IL6ST, FRK, JAK1, GNAS and STAT3 mutations. At the cellular level, we observed an overload of fatty acids linked to increased synthesis induced by $H N F 1 A$ inactivation in the tumor.

On a pathological level and in imaging, marked diffuse homogenous steatosis was present in HHCA, without cytological abnormalities or inflammatory infiltrates [30].

Using immunochemistry, we diagnosed HHCA when confronted with loss of expression of FABP1 in tumor hepatocytes, which were highly expressed in adjacent nontumor liver (Figure 1) [31].

On MRI, HHCA shows a diffuse signal dropout on an opposed phase T1-weighted chemical shift sequence and a fat-suppressed sequence compared with in-phase images due to the presence of fat in the lesion. The signal on T2weighted images is more variable, usually slightly hyperintense on no-fat-suppressed images, and iso/hypointense on fat-suppressed images. After contrast medium injection, moderate enhancement is frequently observed in the arterial phase, but disappears during delayed phases ('pseudo-washout' due to fat content) (Figure 2). Hence, noninvasive diagnosis of this molecular subgroup is possible using MRI [32-34]. 


\begin{tabular}{|c|c|c|c|c|c|c|c|c|c|}
\hline $\begin{array}{l}\text { HCA } \\
\text { classification }\end{array}$ & Frequency & Mutations & $\begin{array}{l}\text { Pathway } \\
\text { disregulated }\end{array}$ & Risk factors & Clinical features & $\begin{array}{l}\text { Histological } \\
\text { features }\end{array}$ & $\begin{array}{l}\text { Immunohistochemical } \\
\text { markers }\end{array}$ & Imaging (MRI) & Complications \\
\hline $\mathrm{H}-\mathrm{HCA}$ & $30-35 \%$ & $\begin{array}{l}\text { HNF1A } \\
\text { biallelic in- } \\
\text { activation }\end{array}$ & $\begin{array}{l}\text { Disturbance in } \\
\text { metabolic } \\
\text { profile }\end{array}$ & $\begin{array}{l}\text { HNF1A } \\
\text { germline } \\
\text { mutations } \\
\text { OC }\end{array}$ & $\begin{array}{l}\text { Women: familial } \\
\text { adenomatosis } \\
\text { (HNF1A } \\
\text { germline) }\end{array}$ & $\begin{array}{l}\text { Tumor, diffuse } \\
\text { steatosis }\end{array}$ & $\begin{array}{l}\text { Decreased FABP1 } \\
\text { expression in the } \\
\text { tumor }\end{array}$ & $\begin{array}{l}\text { T1 chemical } \\
\text { shift sequence: } \\
\text { signal dropout } \\
\text { on opposed } \\
\text { Phase I }\end{array}$ & $\begin{array}{l}\text { No risk of } \\
\text { malignant } \\
\text { transformation } \\
\text { if } \mathrm{HHCA}<5 \mathrm{~cm}\end{array}$ \\
\hline I-HCA & $30-35 \%$ & $\begin{array}{l}\text { IL6ST }(65 \%) \\
\text { FRK }(10 \%) \\
\text { STAT3 }(5 \%) \\
\text { GNAS }(5 \%) \\
\text { JAK1 }(2 \%)\end{array}$ & IL6/JAK/STAT & $\begin{array}{l}\text { OC } \\
\text { High alcohol } \\
\text { consump- } \\
\text { tion } \\
\text { Obesity }\end{array}$ & $\begin{array}{l}\text { Inflammatory } \\
\text { syndrome }\end{array}$ & $\begin{array}{l}\text { Inflammatory } \\
\text { infiltrates } \\
\text { Dystrophic } \\
\text { arteries } \\
\text { Sinusoidal } \\
\text { dilatation }\end{array}$ & $\begin{array}{l}\text { Tumor overexpression } \\
\text { of SAA/CRP }\end{array}$ & $\begin{array}{l}\text { Hyperintense } \\
\text { signal on T2, } \\
\text { arterial } \\
\text { enhancement } \\
\text { persisting in } \\
\text { delayed phases }\end{array}$ & - \\
\hline $\begin{array}{l}\beta \text {-catenin } \\
\text { HCA exon } 3\end{array}$ & $7 \%$ & $\begin{array}{l}\text { Exon } 3 \\
\text { CTNNB1 } \\
\text { mutation }\end{array}$ & $\begin{array}{l}\text { Strong } \\
\beta \text {-catenin } \\
\text { activation }\end{array}$ & $\begin{array}{l}\text { Androgen } \\
\text { Liver } \\
\text { vascular } \\
\text { disease }\end{array}$ & $\begin{array}{l}\text { Male } \\
\text { Only one tumor } \\
\text { Young patient }\end{array}$ & $\begin{array}{l}\text { Cellular atypia } \\
\text { Pseudo- } \\
\text { glandular } \\
\text { formation } \\
\text { Cholestasis }\end{array}$ & $\begin{array}{l}\text { Nuclear } \beta \text {-catenin } \\
\text { Increased glutamine } \\
\text { synthase expression }\end{array}$ & - & $\begin{array}{l}\text { High risk of } \\
\text { malignant } \\
\text { transformation } \\
\text { in HCC }\end{array}$ \\
\hline $\begin{array}{l}\beta \text {-catenin } \\
\text { HCA exon } \\
7-8\end{array}$ & $3 \%$ & $\begin{array}{l}\text { Exon 7-8 } \\
\text { CTNNB1 } \\
\text { mutation }\end{array}$ & $\begin{array}{l}\text { Weak } \\
\beta \text {-catenin } \\
\text { activation }\end{array}$ & OC & $\begin{array}{l}\text { Only one tumor } \\
\text { Young patient }\end{array}$ & - & $\begin{array}{l}\text { Faint glutamine } \\
\text { synthase expression }\end{array}$ & - & - \\
\hline $\begin{array}{l}\text { Sonic } \\
\text { hedgehog } \\
\text { HCA }\end{array}$ & $4 \%$ & $\begin{array}{l}\text { INBHE/GLI1 } \\
\text { fusion }\end{array}$ & $\begin{array}{l}\text { Sonic } \\
\text { hedgehog } \\
\text { activation }\end{array}$ & $\begin{array}{l}\text { OC } \\
\text { Obesity }\end{array}$ & - & Hemorrhage & - & - & Bleeding \\
\hline $\begin{array}{l}\text { Unclassified } \\
\text { HCA }\end{array}$ & $7 \%$ & - & - & - & - & - & - & - & - \\
\hline
\end{tabular}

A total of $50 \%$ of CTNNB1-mutated HCA (either in exon 3 or in exon $7 / 8$ ) are also inflammatory.

CRP: C reactive protein; HCA: Hepatocellular adenoma; HCC: Hepatocellular carcinoma; HHCA: HNF1A-inactivated hepatocellular adenoma; HNF1A: Hepatocyte nuclear factor 1A; IHCA: Inflammatory hepatocellular adenoma; OC: Oral contraception; SAA: Serum amyloid A.

\section{Inflammatory HCA}

IHCA represents $40-50 \%$ of all adenomas and is characterized by constitutive uncontrolled activation of the inflammatory IL6/JAK/STAT pathway (17) (Table 1) [30]. IHCA is linked to several mutations, separate from one another, in various oncogenes that belong to this pathway: IL6ST (65\%), FRK (10\%), STAT3 (5\%), GNAS (5\%) and JAK1 (2\%) [35-37]. These HCAs are frequently associated with obesity, metabolic syndrome and high alcohol consumption [38].

On histological examination, IHCAs are characterized by inflammatory infiltrates, dystrophic vessels and sinusoidal dilatations [39].

In immunochemistry, inflammatory markers have been described as satisfactory tools for diagnosis of this HCA subtype in routine examinations. SAA and CRP, two proteins of the acute phase of inflammation, are overexpressed in the cytoplasm of tumor hepatocytes (Figure 1) [31]. A minority of FNH might also harbor focal positivity of SAA [40].

On MRI, IHCA is characterized by marked hyperintensity on T2-weighted sequences, with occasional and more severe hyperintensity in the outer part of the lesions ('atoll sign' due to sinusoidal dilatation areas), together with strong arterial enhancement persistent in the portal venous and delayed phases (Figure 3) [32,33]. A combination of these two MRI findings enables noninvasive diagnosis of IHCA with sensitivity between 85 and $88 \%$ and specificity between 88 and $100 \%[32,33]$.

\section{$\beta$-catenin-mutated HCA exon 3}

The $\mathrm{Wnt} / \beta$-catenin pathway is responsible for liver zonation, liver embryogenesis, amino acid metabolism and hepatic regeneration $[41,42]$. Moreover, the $\mathrm{Wnt} / \beta$-catenin pathway is a key pathway activated in several malignancies, including colorectal cancer, hepatocellular carcinoma, breast cancer and medulloblastoma [42].

A total of $10-15 \%$ of HCA harbor an activating mutation of $\beta$-catenin on exon 3, responsible for uncontrolled activation of the pathway (Table 1) [20,43].

In an inactivated state, $\beta$-catenin (encoded by CTNNB1) is phosphorylated by the APC/GSK3B/AXIN1 complex, which leads to degradation of $\beta$-catenin by the proteasome. In the case of activating mutations of CTNNB1, phosphorylation of $\beta$-catenin is impaired and, instead of being degraded in proteasomes, $\beta$-catenin 

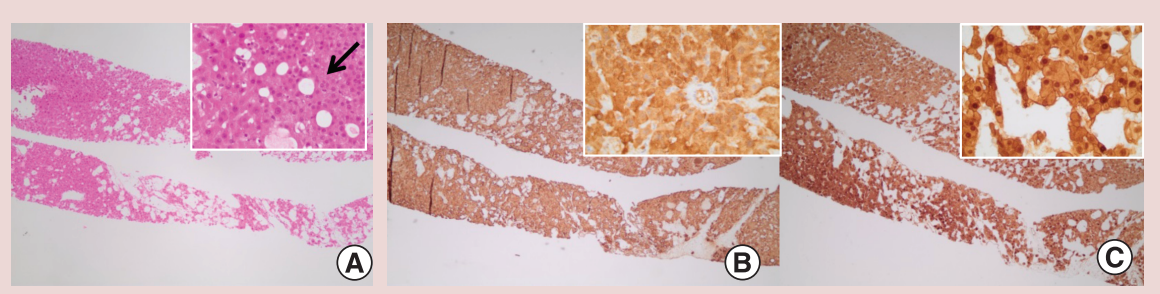

(A)
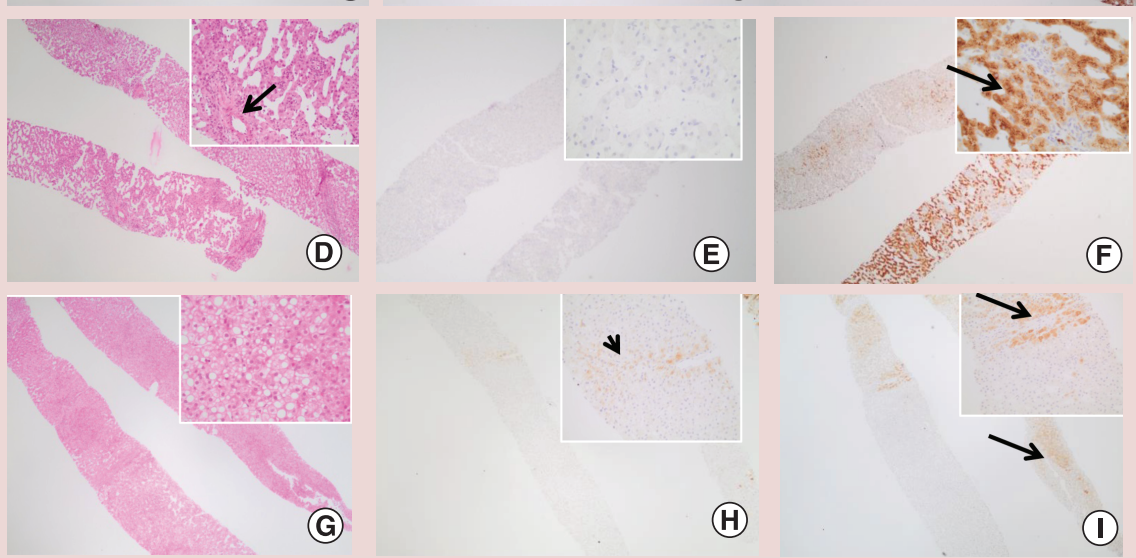

(H)

(1)

Figure 1. Biopsy samples of hepatocellular adenomas. $\beta$-catenin exon-3-mutated hepatocellular adenoma: thick trabeculae with mild nuclear atypia and pseudo-gland (arrow) are frequently observed (A). Strong diffuse staining for glutamine synthase (B), as well as nuclear translocation of $\beta$-catenin (C), when present, enable diagnosis.

Inflammatory hepatocellular adenoma with sinusoidal dilatations, inflammatory foci and isolated arteries (arrow) (D). No glutamine synthase expression is observed (E). Immunostaining with amyloid A (SAA) shows strong cytoplasmic staining; normal adjacent liver in the upper part is negative for SAA (F). HNF1A-inactivated adenoma with tumor steatosis (G). Glutamine synthase $(\mathbf{H})$ is negative or weak (similar to adjacent nontumor liver with perivenular staining, arrow). In contrast to the adjacent nontumor liver (I, arrows), HNF1a-inactivated adenoma characteristically lacks L-FABP staining in the tumor (I).

SAA: Serum amyloid A.

translocates into the nucleus and acts as a co-transcription factor to foster its oncogenic effect [42]. This explains the localization of $\beta$-catenin in the nucleus observed in $\beta$-catenin-mutated HCA.

CTNNB1-activating mutations in exon 3 are completely exclusive of HNF1A mutations and CTNNB1-activating mutations in exons 7 and 8 , whereas $50 \%$ of $\beta$-catenin-mutated HCA on exon 3 also show activation of the inflammatory pathway [21]. Consequently, in clinical practice, activation of the Wnt/ $\beta$-catenin pathway should be sought when confronted with inflammatory HCA [21].

On a pathological level, we observed cellular atypia, pseudoglandular formations and cholestasis (Figure 1) [30].

On immunochemistry, $\beta$-catenin-mutated HCA exon 3 is defined by nuclear translocation of $\beta$-catenin and overexpression of glutamine synthase, a target gene of the pathway (Figures $1 \& 4$ ) [31]. However, nuclear translocation of $\beta$-catenin could be lacking in HCA with CTNNB1 exon 3. Moreover, some cases of HCA with CTNNB1 exon 3 have patchy positive glutamine synthase, and S45CTNNB1 mutations frequently harbor diffused heterogeneous glutamine synthase. Consequently, $\beta$-catenin and glutamine synthase immunostaining are sometimes difficult to interpret, especially on tumor biopsy $[40,44]$. Despite the high specificity of these two markers, sensitivity may be insufficient (75-85\%) for diagnosis of $\beta$-catenin exon 3 mutations, and molecular biology may be required for definitive diagnosis in difficult cases [45].

These HCA are more frequent in men, and risk of malignant transformation in HCC attains 40\%, an incidence higher than for other molecular subtypes of HCA $[20,31,46]$. In HCC derived from HCA, the CTNNB1 exon 3 mutation is the earliest genetic alteration, whereas mutations in the promoter of telomerase reverse transcriptase seem to be involved in the final step of transition between HCA and HCC $[36,47]$. Consequently, identification of this subtype of HCA is highly relevant in clinical practice and can be performed only by molecular analysis or immunohistochemistry, since no specific radiological features have yet been described. 

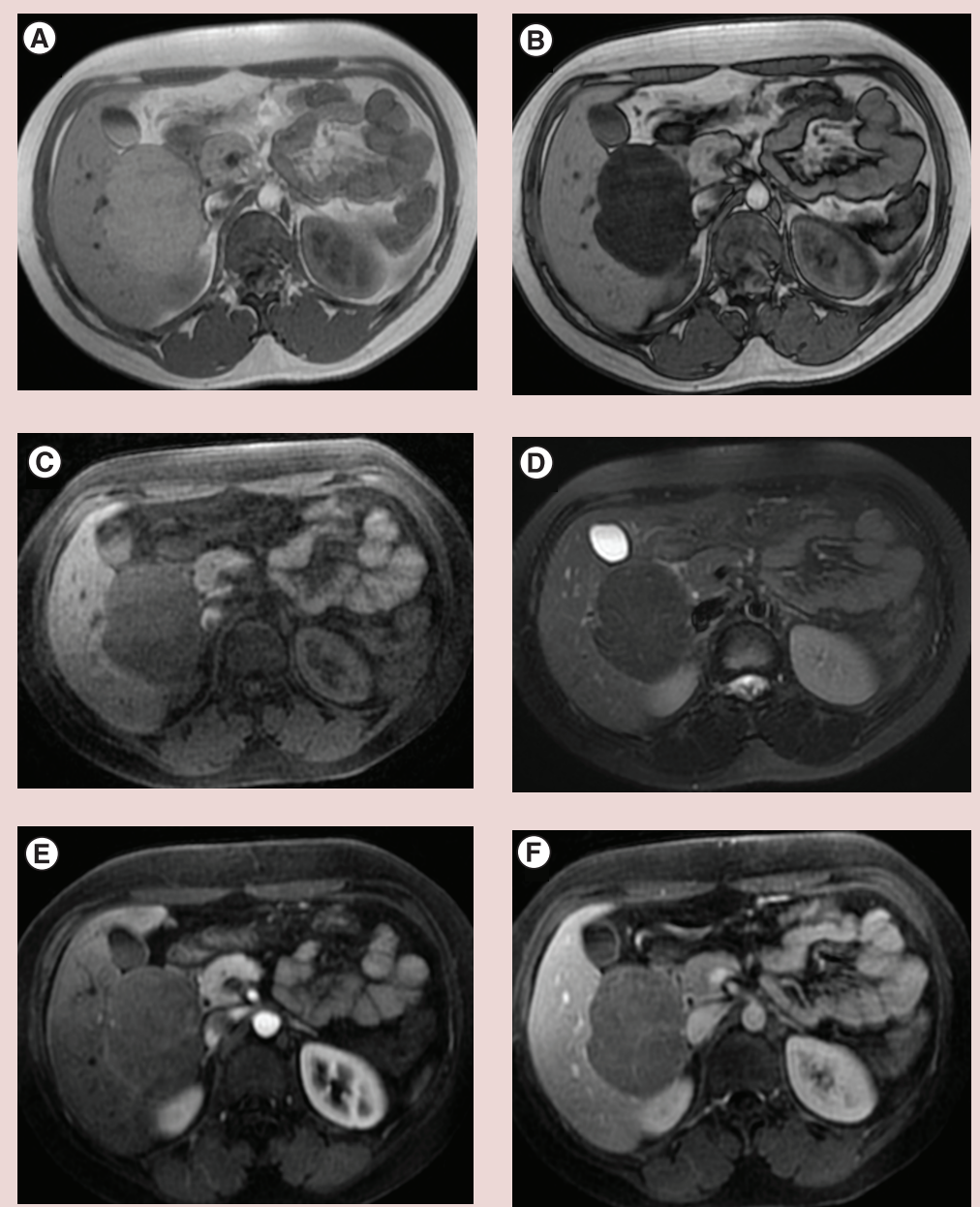

Figure 2. Imaging features of HNF1A inactivated hepatocellular adenoma. Large HNF1A-inactivated hepatocellular adenoma (HCA) in a 26-year-old woman. In chemical shift T1-weighted sequence, HCA has moderate hyperintensity in-phase (A), with a marked signal dropout on opposed-phase images (B). The lesion is hypointense in both T1 (C) and T2 (D) fat-suppressed sequences due to the lipid content. After contrast medium injection, there is only slight arterial enhancement $(E)$, but the lesion remains hypointense compared with the normal liver on portal venous phase (F).

\section{$\beta$-catenin-mutated HCA exons 7 and 8}

A total of $10 \%$ of HCAs have a mutation of CTNNB1 located on exon 7 or 8 (Table 1) [45]. These $\beta$-catenin mutations are characterized by mild activation of the $\mathrm{Wnt} / \beta$-catenin pathway, and are exclusive of mutations of $\beta$-catenin on exon 3. Half of HCAs with $\beta$-catenin-mutated HCA exons 7 and 8 also have an inflammatory phenotype and share the features of each subgroup [36,45]. At histology and immunochemistry, there are no specific markers (no nuclear translocation of $\beta$-catenin and only slightly increased glutamine synthase expression) [45]. Moreover, this subtype has not been associated with higher risk of malignant transformation; consequently, its identification in clinical practice does not seem useful at this time [36].

\section{Sonic hedgehog HCA}

Recently, a new subgroup has been identified, representing $4 \%$ of all HCA and defined by activation of the sonic hedgehog pathway due to fusion of the promoter of INHBE with GLII (Table 1) [21]. The sonic hedgehog pathway is involved in lipid metabolism and in regeneration in the liver. In a quiescent state, receptor PTCH is inhibited by SMO, and this inhibition is released when the hedgehog ligand binds to PTCH. It induces translocation into the nucleus of transcription factor GLI1, which controls expression of a network of genes [48]. 

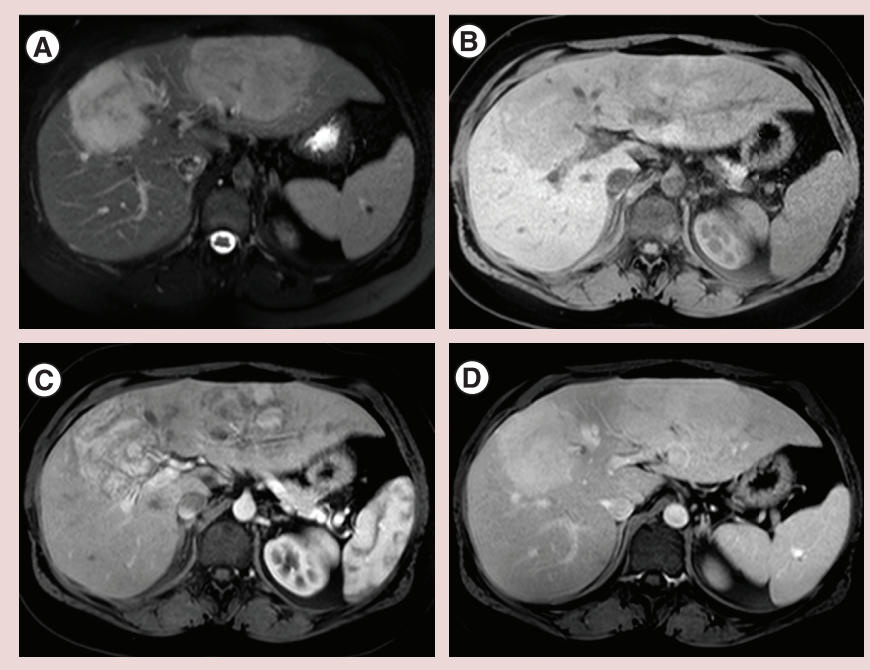

Figure 3. Imaging features of inflammatory hepatocellular adenoma. Two large inflammatory hepatocellular adenomas in a 33-year-old woman. Note: typical MRI appearance with marked hyperintensity on T2-weighted images (A), together with hypointensity on T1-weighted fat-suppressed images (B). After contrast medium injection, there is strong heterogeneous arterial enhancement of the two lesions (C) that persists in the portal venous phase (D).

Sonic hedgehog HCA was characterized by overexpression of GLII due to its fusion with the $5^{\prime}$ end of INHBE, a highly expressed gene located upstream of GLI1 [21]. This new subgroup is associated with obesity, and with both histological hemorrhage and symptomatic bleeding [21,22]. However, sonic hedgehog HCA does not currently have any specific immunohistochemical markers or radiological features useful for routine identification [21].

\section{Unclassified HCA}

Fewer than $10 \%$ of HCA remain unclassified (Table 1) [22].

\section{Translation into clinical practice}

Identification of new risk factors

The principal risk factor in HCA development is estrogen exposure, with long-term use of oral contraception, but also female sex and pregnancy [2].

Androgen intake, glycogen storage disease, hepatic vascular disease, McCune-Albright disease (characterized by fibrous bone dysplasia, 'café au lait' skin macula and pituitary and thyroid adenomas due to somatic postzygotic mosaic GNAS mutation) and an HNF1A germline mutation with MODY 3 diabetes are also involved in HCA occurrence $[2,12,37]$.

Several cases of familial liver adenomatosis have been described worldwide, consistently linked to the presence of an $H N F 1 A$ germline mutation, and sometimes to MODY 3 diabetes.

Thus, detection of liver adenomatosis with HNF1A-mutated HCA in a patient requires family screening to search for familial adenomatosis, MODY 3 diabetes, and the HNF1A germline mutation [28].

Liver adenomatosis may also be associated with glycogen storage disease. To our knowledge, this disease has never been associated with $H N F 1 A$-inactivated HCA [49].

Furthermore, specific genetic diseases are associated with a specific subtype of HCA: MODY3 with HHCA, McCune-Albright syndrome with IHCA and type 1 glycogen storage disease with IHCA, $\beta$-mutated HCA (exon 3 or exon 7/8) or unclassified HCA [49].

Otherwise, obesity and high alcohol intake are risk factors in inflammatory and sonic hedgehog HCA (25) [31]. Interestingly, tumor size may decrease in up to a third of patients in case of weight reduction due to diet or bariatric surgery [50].

Several cases of regression of HCA after withdrawal of estrogens or androgens have been observed, suggesting the fundamental role of hormones in HCA development [9,10]. Strikingly, regression of HCA and HCC mutated for CTNNB1 in exon 3 has been observed after androgen withdrawal [9]. 

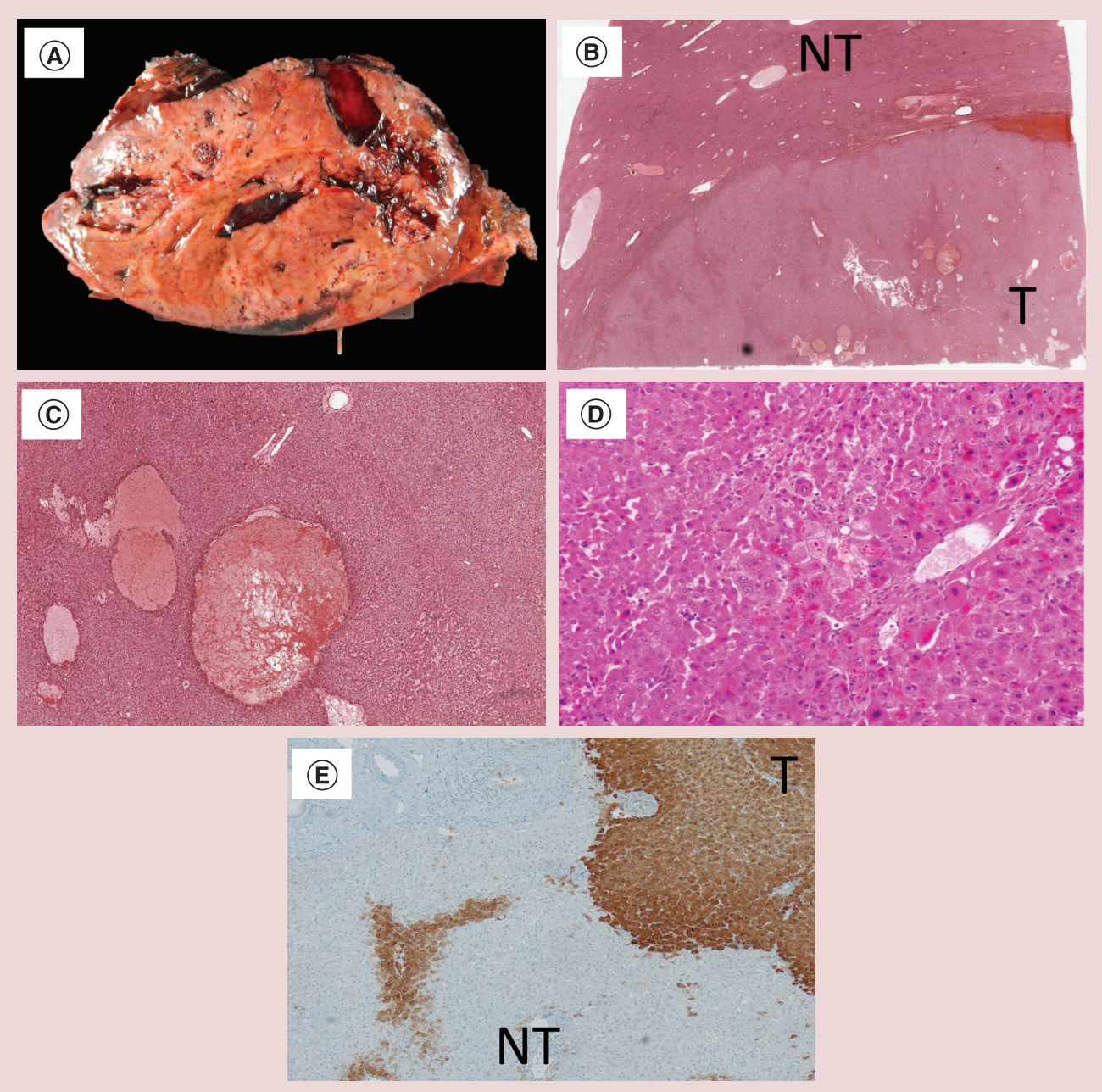

Figure 4. Surgical samples of sonic hedgehog hepatocellular adenoma and $\beta$-catenin exon-3-mutated hepatocellular adenoma. Sonic hedgehog hepatocellular adenoma: macroscopic view of a large liver nodule with hemorrhagic areas (A). Low magnification demonstrating a sharply limited hepatocellular nodule with hemorrhagic areas (B) and (C). $\beta$-catenin exon-3-mutated HCA with cellular atypia: microscopic examination shows a

well-differentiated hepatocellular tumor with cellular atypia (large, hyperchromatic nuclei and bi-nucleated cells) (D). Glutamine synthase is strongly expressed in the tumor (E).

HCA: Hepatocellular adenoma; NT: Nontumor; T: Tumor.

Identification of risk factors helps to define both preventive measures and screening programs:

- Oral contraception and androgen intake must be discontinued;

- Weight reduction is a key point in IHCA and sonic hedgehog HCA. Reduction in size has been described after weight loss following bariatric surgery;

- Screening for the $H N F 1 A$ germline mutation and familial adenomatosis in $H N F 1 A$-inactivated adenomatosis is recommended;

- Screening of HCA in glycogenosis (50\% of patients with glycogenesis type IA have adenomatosis at adulthood, sometimes associated with malignant transformation) should be performed.

\section{Diagnosis}

Currently, HCA is frequently discovered following abdominal pain, or incidentally at imaging [31,51]. More rarely, HCA is also revealed by hemorrhage or malignant transformation. Liver enzymes are normal in almost half of the cases, and tumor markers (AFP, ACE and CA19-9) are negative [31,51]. In the subgroup of IHCA, GGT, alkaline 


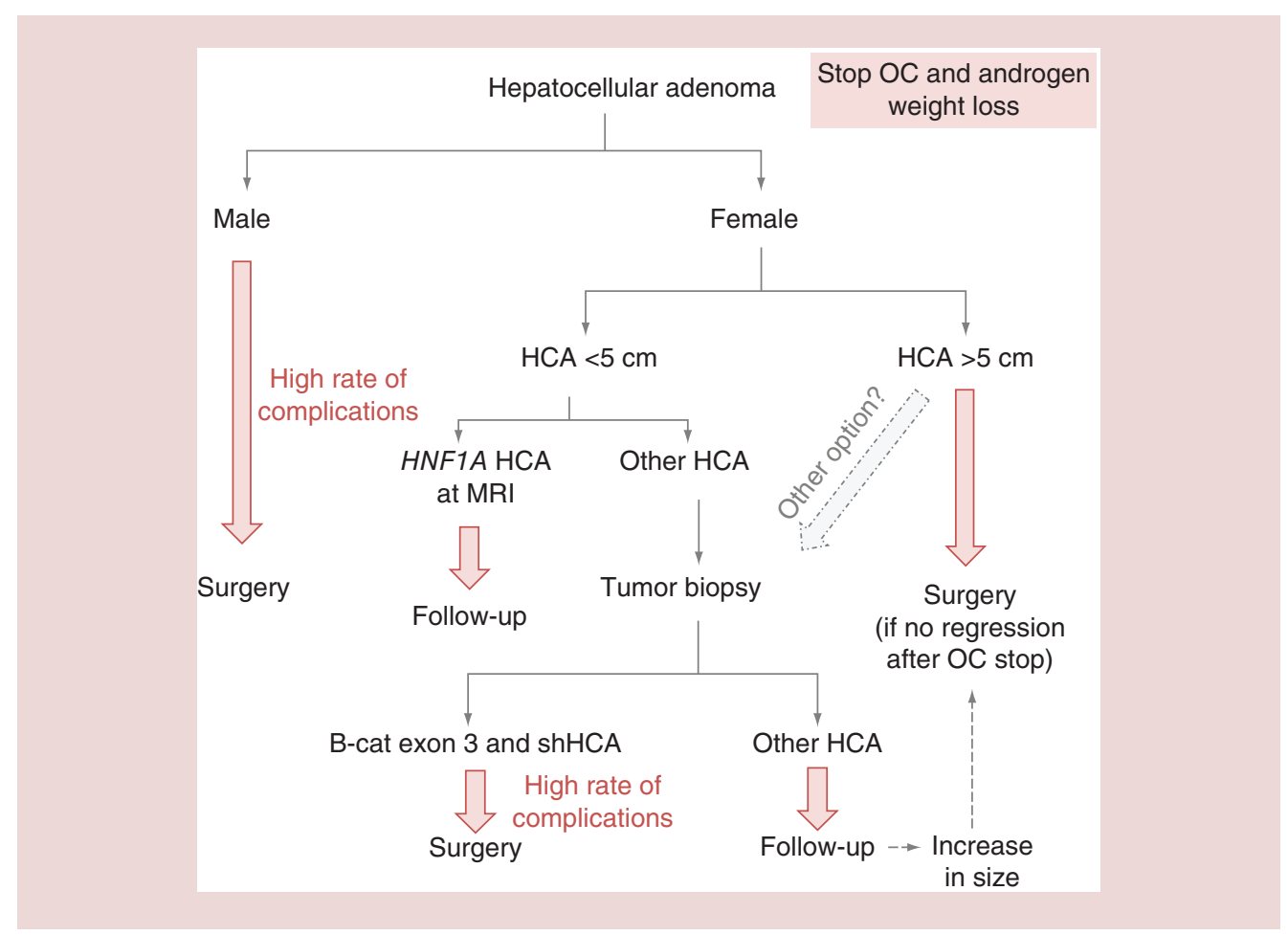

Figure 5. Algorithm for the treatment of hepatocellular adenoma based on molecular classification. We propose an algorithm for treatment of HCA based on our knowledge of molecular classification.

HCA: Hepatocellular adenoma; OC: Oral contraception; shHCA: Sonic hedgehog hepatocellular adenoma.

phosphatase and CRP are frequently elevated [21]. Occasionally, IHCA is associated with a paraneoplastic syndrome, including an inflammatory syndrome and anemia that regress after surgical removal of the tumors [52].

The diagnosis of HCA relies mainly on histological analysis, but differential diagnosis with focal nodular hyperplasia or well-differentiated hepatocellular carcinoma may sometimes be complicated, even for expert pathologists [53].

In clinical practice, molecular classification is currently used by pathologists, and four key immunohistochemical markers (SAA, FABP1, glutamine synthase and $\beta$-catenin) are useful to determine the most important subgroups of HCA and exclude the diagnosis of focal nodular hyperplasia (Table $1 \&$ Figure 1). These markers can be used both on surgical specimens and on liver biopsy [54-58]. Several groups in Belgium, the UK, the USA, The Netherlands, Japan, and China have shown that the different molecular subgroups of HCA are observed worldwide. However, the proportion of each molecular subtype may vary, with less frequent HNF1A-inactivated HCA in Japan than in other countries [55-59].

However, we should stress that immunohistochemistry is unable to detect $\beta$-catenin-mutated HCA on exons 7-8 and sonic hedgehog HCA [21]. Interestingly, a subset of patients harbors multiple HCAs. In $70 \%$ of these patients, HCA belong to the same molecular subclasses. When confronted with different molecular subclasses in the same patient, CTNNB1 exon 3 mutation was primarily observed in the largest nodule [21].

Imaging may also be a useful tool for classifying $\mathrm{HCA}$, and MRI characteristics are highly relevant for diagnosing HHCA and IHCA (Figures 2 \& 3) [32-34]. However, typical imaging of IHCA at MRI did not exclude the presence of a concomitant $\beta$-catenin mutation on exon 3 , associated with high risk of malignant transformation.

\section{Therapeutic management according to risk stratification}

Use of molecular classification for therapeutic strategies appears relevant, since the risk of complications depends on the HCA subtype (Figure 5).

CTNNB1-mutated HCA in exon 3 has a higher risk of malignant transformation, while sonic hedgehog HCA frequently shows symptomatic bleeding or tumor histological bleeding [21,46]. The risk of hemorrhaging is directly linked to tumor size and to the molecular subgroup; in the literature, a cut-off of $5 \mathrm{~cm}$ in size was associated with 
risk of bleeding, but this remains subject to debate $[16,18,21,51]$. Male sex and $\beta$-catenin-mutated HCA in exon 3 have been significantly associated with higher risk of malignant transformation [51].

One of the initial treatments consisted of arrest of oral contraception and/or androgens $[9,10]$.

For a number of years, surgical treatment was proposed whatever the tumor size if no regression was observed after hormone discontinuation, due to the unpredictable evolution of these lesions.

Recently, a conservative approach has been preferred instead of surgery in all cases $[5,51,60]$. However, management of HCA remains controversial due to the lack of strong evidence in the literature [6,61]. Therapeutic strategy is guided by the risk of complications. Tumor size and localization, subtype of the molecular classification, and sex are the three main factors that determine therapeutic strategy (Figure 5) [21]. Currently, a laparoscopic approach is preferred rather than open surgery, since it is associated with reduced morbidity, reduced blood loss and need for transfusion, reduced length of hospital stay, and less esthetic damage in young women [62].

In men, all HCA should be surgically removed due to the high risk of malignant transformation $[4,43,51]$.

Radiofrequency ablation (RFA) has also been proposed by several authors, in combination with or as an alternative to surgery for treatment of small HCA. Only small series are available in the literature, having no correlation with the molecular classification of HCA; potential indications for RFA remain unclear [63]. As a radical treatment, RFA should be proposed based on the risk of complication, depending on HCA subtype and molecular classification. Potential advantages include a satisfactory safety profile, high cost-effectiveness and acceptability for esthetic reasons, particularly in young women [64]. This strategy must also be discussed in case of morbid obesity, or liver steatosis associated with morbidity after major surgery. One major disadvantage is that, unlike surgery, no definitive histologic or molecular analysis of the entire tumor specimen can be performed. More studies are needed to clarify the possible use of RFA in patients with HCA.

In women with large HCA (over $5 \mathrm{~cm}$ ) [65], several solutions are available and should be discussed by a multidisciplinary tumor board:

- Systematic resection via surgery;

- Surgery after 6-12 months of estroprogestative withdrawal if HCA does not regress;

- Surgery only for symptomatic patients, or HCA with high risk of complications defined by molecular classification.

In women with small HCA (less than $5 \mathrm{~cm}$ ), surgical indication should be guided by the presence of the $\beta$-catenin exon 3 mutation, whereas follow-up could be proposed for the other molecular subtypes [20,66]. In our series of $511 \mathrm{HCA}, \mathrm{H}-\mathrm{HCAs}$ of less than $5 \mathrm{~cm}$ were never associated with malignant transformation and were able to be diagnosed by MRI without the need for tumor biopsy [21]. In other cases, tumor biopsy was proposed to search for the $\beta$-catenin mutation and to better assess the risk of malignant transformation $[8,21]$. However, one limitation that remains is the small number of laboratories worldwide that perform molecular analysis of HCA in clinical care.

Liver transplantation is required only in very select cases of glycogenosis type $1 \mathrm{~A}$ or in unresectable HCC developing on HCA [67]. For liver adenomatosis or multiple HCA, risk of complications is almost the same as that for HCA alone, and therapeutic strategy may follow the same rules as for HCA alone, mixing gender, size and molecular subtype [21,51]. HCA is not a contra-indication for pregnancy, since risk of bleeding during pregnancy is low or even inexistent in recently published series [51]. However, if possible, resection of HCA should be discussed by a multidisciplinary tumor board prior to pregnancy.

\section{Conclusion \& future perspective}

In the past few years, major breakthroughs have occurred in our understanding of the physiopathology of HCA. A limited number of genetic alterations affecting driver genes (one to two per tumor) are required to promote HCA development. HCA is no longer considered a homogeneous disease; rather, it is described as a complex entity divided into several molecular subgroups linked to risk factors, histological and imaging features, and clinical behavior that redefine the nosology of the disease. Four signaling pathways involved in benign liver tumorigenesis have emerged: an HNF1A inactivation link with metabolic disorder; Wnt/ $\beta$-catenin pathway activation; IL-6/JAK/STAT3 pathway activation; and sonic hedgehog pathway activation.

Specific inhibition of drivers in each pathway by targeted therapies represents a new avenue of treatment of nonresectable HCA and liver adenomatosis. For example, preclinical data have shown that JAK1 and Src inhibitors may promptly shut down activation of the inflammatory pathway in preclinical models, but this requires validation 
in clinical trials in humans with IHCA [68]. Moreover, only a few patients exposed to estrogens developed HCA, which suggests that other genetic and/or environmental factors are required to promote HCA development. However, except for $H N F 1 A$ germline mutations and glycogenosis type 1A, a genetic predisposition toward HCA remains to be explored. Finally, based on gender, tumor size, and molecular classification, a new therapeutic strategy has been proposed for optimizing management of patients with HCA that requires validation in multicentric prospective cohorts.

\section{Acknowledgements}

This work supported by Association pour la recherche contre le cancer (2003), Société Nationale Française de Gastro-Entérologie (2005), Inca (2006), GENTHEP Inserm Network (2003-2008), Equipe Labellisée Ligue Contre le Cancer, Labex Oncolmmunology Investissement d'Avenir. The French Liver Biobanks Network-INCa, BB-0033-00085, Hepatobio Bank. Fondation BettencourtSchueller coup d'élan pour la recherche.

\section{Financial \& competing interests disclosure}

The authors have no relevant affiliations or financial involvement with any organization or entity with a financial interest in or financial conflict with the subject matter or materials discussed in the manuscript. This includes employment, consultancies, honoraria, stock ownership or options, expert testimony, grants or patents received or pending, or royalties.

No writing assistance was utilized in the production of this manuscript

\section{Open access}

This work is licensed under theAttribution-NonCommercial-NoDerivatives 4.0 Unported License. To view a copy of this license, visit http://creativecommons.org/licenses/by-nc-nd/4.0/

\section{References}

Papers of special note have been highlighted as: $\bullet$ of interest; $\bullet \bullet$ of considerable interest

1. Edmondson HA, Henderson B, Benton B. Liver-cell adenomas associated with use of oral contraceptives. N. Engl. J. Med. 294, 470-472 (1976).

-. Seminal description of the relationship between hepatocellular adenoma (HCA) and oral contraception.

2. Nault JC, Bioulac-Sage P, Zucman-Rossi J. Hepatocellular benign tumors from molecular classification to personalized clinical care. Gastroenterology 144, 888-902 (2013).

3. Rooks JB, Ory HW, Ishak KG et al. Epidemiology of hepatocellular adenoma. The role of oral contraceptive use. JAMA 242, 644-648 (1979).

4. Belghiti J, Cauchy F, Paradis V, Vilgrain V. Diagnosis and management of solid benign liver lesions. Nat. Rev. Gastroenterol. Hepatol. 11, 737-749 (2014).

5. Cherqui D, Rahmouni A, Charlotte F et al. Management of focal nodular hyperplasia and hepatocellular adenoma in young women: a series of 41 patients with clinical, radiological, and pathological correlations. Hepatology 22, 1674-1681 (1995).

6. European Association for the Study of the Liver. EASL clinical practice guidelines on the management of benign liver tumours. J. Hepatol. 65, 386-398 (2016).

7. Rooks JB, Ory HW, Ishak KG, Strauss LT, Greenspan JR, Tyler CW Jr. The association between oral contraception and hepatocellular adenoma - a preliminary report. Int. J. Gynaecol. Obstet. 15, 143-144 (1977).

8. Torbenson M, Lee JH, Choti M et al. Hepatic adenomas: analysis of sex steroid receptor status and the Wnt signaling pathway. Mod. Pathol. 15, 189-196 (2002).

9. Svrcek M, Jeannot E, Arrive L et al. Regressive liver adenomatosis following androgenic progestin therapy withdrawal: a case report with a 10-year follow-up and a molecular analysis. Eur. J. Endocrinol. 156, 617-621 (2007).

10. Buhler H, Pirovino M, Akobiantz A et al. Regression of liver cell adenoma. A follow-up study of three consecutive patients after discontinuation of oral contraceptive use. Gastroenterology 82, 775-782 (1982).

11. Labrune P, Trioche P, Duvaltier I, Chevalier P, Odievre M. Hepatocellular adenomas in glycogen storage disease type I and III: a series of 43 patients and review of the literature. J. Pediatr. Gastroenterol. Nutr. 24, 276-279 (1997).

12. Sempoux $\mathrm{C}$, Paradis V, Komuta $\mathrm{M}$ et al. Hepatocellular nodules expressing markers of hepatocellular adenomas in Budd-Chiari syndrome and other rare hepatic vascular disorders. J. Hepatol. 63, 1173-1180 (2015).

13. Flejou JF, Barge J, Menu Y et al. Liver adenomatosis. An entity distinct from liver adenoma? Gastroenterology 89, 1132-1138 (1985).

- First clinical description of liver adenomatosis.

14. Chiche L, Dao T, Salame E et al. Liver adenomatosis: reappraisal, diagnosis, and surgical management: eight new cases and review of the literature. Ann. Surg. 231, 74-81 (2000). 
15. Gyorffy EJ, Bredfeldt JE, Black WC. Transformation of hepatic cell adenoma to hepatocellular carcinoma due to oral contraceptive use. Ann. Intern. Med. 110, 489-490 (1989).

16. Bieze M, Phoa SS, Verheij J, van Lienden KP, van Gulik TM. Risk factors for bleeding in hepatocellular adenoma. Br. J. Surg. 101, 847-855 (2014).

17. Farges O, Ferreira N, Dokmak S, Belghiti J, Bedossa P, Paradis V. Changing trends in malignant transformation of hepatocellular adenoma. Gut 60, 85-89 (2011).

18. van Aalten SM, de Man RA, JN IJ, Terkivatan T. Systematic review of haemorrhage and rupture of hepatocellular adenomas. Br. J. Surg. 99, 911-916 (2012).

-. Excellent review of literature on the risk of HCA bleeding.

19. Kakar S, Grenert JP, Paradis V, Pote N, Jakate S, Ferrell LD. Hepatocellular carcinoma arising in adenoma: similar immunohistochemical and cytogenetic features in adenoma and hepatocellular carcinoma portions of the tumor. Mod. Pathol. 27, 1499-1509 (2014).

- Interesting description of molecular features of HCA and hepatocellular carcinoma and difficulties in distinguishing HCA from hepatocellular carcinoma.

20. Zucman-Rossi J, Jeannot E, Nhieu JT et al. Genotype-phenotype correlation in hepatocellular adenoma: new classification and relationship with HCC. Hepatology 43, 515-524 (2006).

-• First description of the molecular classification of HCA and correlation with histological and clinical features.

21. Nault JC, Couchy G, Balabaud C et al. Molecular classification of hepatocellular adenoma associates with risk factors, bleeding, and malignant transformation. Gastroenterology 152, 886e880-886e894 (2017).

22. Nault JC, Paradis V, Cherqui D, Vilgrain V, Zucman-Rossi J. Molecular classification of hepatocellular adenoma in clinical practice. J. Hepatol. 67, 1074-1083 (2017).

23. Nault JC, Zucman Rossi J. Molecular classification of hepatocellular adenomas. Int. J. Hepatol. 2013, 315947 (2013).

24. Bluteau O, Jeannot E, Bioulac-Sage P et al. Bi-allelic inactivation of TCF1 in hepatic adenomas. Nat. Genet. 32, 312-315 (2002).

25. Pelletier L, Rebouissou S, Paris A et al. Loss of hepatocyte nuclear factor 1 alpha function in human hepatocellular adenomas leads to aberrant activation of signaling pathways involved in tumorigenesis. Hepatology 51, 557-566 (2010).

26. Rebouissou S, Imbeaud S, Balabaud C et al. HNF1 alpha inactivation promotes lipogenesis in human hepatocellular adenoma independently of SREBP-1 and carbohydrate-response element-binding protein (ChREBP) activation. J. Biol. Chem. 282, 14437-14446 (2007).

27. Yamagata K, Oda N, Kaisaki PJ et al. Mutations in the hepatocyte nuclear factor-1 alpha gene in maturity-onset diabetes of the young (MODY3). Nature 384, 455-458 (1996).

28. Bacq Y, Jacquemin E, Balabaud C et al. Familial liver adenomatosis associated with hepatocyte nuclear factor 1alpha inactivation. Gastroenterology 125, 1470-1475 (2003).

29. Reznik Y, Dao T, Coutant R et al. Hepatocyte nuclear factor-1 alpha gene inactivation: cosegregation between liver adenomatosis and diabetes phenotypes in two maturity-onset diabetes of the young (MODY)3 families. J. Clin. Endocrinol. Metab. 89, 1476-1480 (2004).

30. Bioulac-Sage $\mathrm{P}$, Rebouissou $\mathrm{S}$, Thomas $\mathrm{C}$ et al. Hepatocellular adenoma subtype classification using molecular markers and immunohistochemistry. Hepatology 46, 740-748 (2007).

- Manuscript on the use of immunohistochemistry and histological features to identify molecular subclasses of HCA.

31. Bioulac-Sage P, Laumonier H, Couchy G et al. Hepatocellular adenoma management and phenotypic classification: the Bordeaux experience. Hepatology 50, 481-489 (2009).

32. Laumonier H, Bioulac-Sage P, Laurent C, Zucman-Rossi J, Balabaud C, Trillaud H. Hepatocellular adenomas: magnetic resonance imaging features as a function of molecular pathological classification. Hepatology 48, 808-818 (2008).

33. Ronot M, Bahrami S, Calderaro J et al. Hepatocellular adenomas: accuracy of magnetic resonance imaging and liver biopsy in subtype classification. Hepatology 53, 1182-1191 (2011).

34. van Aalten SM, Thomeer MG, Terkivatan T et al. Hepatocellular adenomas: correlation of MR imaging findings with pathologic subtype classification. Radiology 261, 172-181 (2011).

35. Pilati C, Amessou M, Bihl MP et al. Somatic mutations activating STAT3 in human inflammatory hepatocellular adenomas. J. Exp. Med. 208, 1359-1366 (2011).

36. Pilati C, Letouze E, Nault JC et al. Genomic profiling of hepatocellular adenomas reveals recurrent FRK-activating mutations and the mechanisms of malignant transformation. Cancer Cell 25, 428-441 (2014).

37. Nault JC, Fabre M, Couchy G et al. GNAS-activating mutations define a rare subgroup of inflammatory liver tumors characterized by STAT3 activation. J. Hepatol. 56, 184-191 (2012).

38. Paradis V, Champault A, Ronot $\mathrm{M}$ et al. Telangiectatic adenoma: an entity associated with increased body mass index and inflammation. Hepatology 46, 140-146 (2007).

39. Paradis V, Benzekri A, Dargere D et al. Telangiectatic focal nodular hyperplasia: a variant of hepatocellular adenoma. Gastroenterology 126, 1323-1329 (2004). 
40. Joseph NM, Ferrell LD, Jain D et al. Diagnostic utility and limitations of glutamine synthetase and serum amyloid-associated protein immunohistochemistry in the distinction of focal nodular hyperplasia and inflammatory hepatocellular adenoma. Mod. Pathol. 27, 62-72 (2014).

41. Thompson MD, Monga SP. WNT/beta-catenin signaling in liver health and disease. Hepatology 45, 1298-1305 (2007).

42. Clevers H, Nusse R. Wnt/beta-catenin signaling and disease. Cell 149, 1192-1205 (2012).

43. Chen YW, Jeng YM, Yeh SH, Chen PJ. P53 gene and Wnt signaling in benign neoplasms: $\beta$-catenin mutations in hepatic adenoma but not in focal nodular hyperplasia. Hepatology 36, 927-935 (2002).

\section{- $\quad$ First description of $\beta$-catenin mutations in HCA.}

44. Hale G, Liu X, Hu J et al. Correlation of exon 3 beta-catenin mutations with glutamine synthetase staining patterns in hepatocellular adenoma and hepatocellular carcinoma. Mod. Pathol. 29, 1370-1380 (2016).

- Description of the limitation of glutamine synthase immunohistochemistry to identify $\beta$-catenin mutations in HCA.

45. Rebouissou S, Franconi A, Calderaro J et al. Genotype-phenotype correlation of CTNNB1 mutations reveals different ss-catenin activity associated with liver tumor progression. Hepatology 64, 2047-2061 (2016).

46. Evason KJ, Grenert JP, Ferrell LD, Kakar S. Atypical hepatocellular adenoma-like neoplasms with beta-catenin activation show cytogenetic alterations similar to well-differentiated hepatocellular carcinomas. Hum. Pathol. 44, 750-758 (2013).

47. Nault JC, Mallet M, Pilati C et al. High frequency of telomerase reverse-transcriptase promoter somatic mutations in hepatocellular carcinoma and preneoplastic lesions. Nat. Commun. 4, 2218 (2013).

48. Amakye D, Jagani Z, Dorsch M. Unraveling the therapeutic potential of the Hedgehog pathway in cancer. Nat. Med. 19, 1410-1422 (2013).

49. Calderaro J, Labrune P, Morcrette G et al. Molecular characterization of hepatocellular adenomas developed in patients with glycogen storage disease type I. J. Hepatol. 58, 350-357 (2013).

50. Dokmak S, Belghiti J. Will weight loss become a future treatment of hepatocellular adenoma in obese patients? Liver Int. 35, 2228-2232 (2015).

51. Dokmak S, Paradis V, Vilgrain V et al. A single-center surgical experience of 122 patients with single and multiple hepatocellular adenomas. Gastroenterology 137, 1698-1705 (2009).

52. Sa Cunha A, Blanc JF, Lazaro E et al. Inflammatory syndrome with liver adenomatosis: the beneficial effects of surgical management. Gut 56, 307-309 (2007).

53. Roux M, Pigneur F, Calderaro J et al. Differentiation of focal nodular hyperplasia from hepatocellular adenoma: role of the quantitative analysis of gadobenate dimeglumine-enhanced hepatobiliary phase MRI. J. Magn. Reson. Imaging 42, 1249-1258 (2015).

54. Bioulac-Sage P, Cubel G, Taouji S et al. Immunohistochemical markers on needle biopsies are helpful for the diagnosis of focal nodular hyperplasia and hepatocellular adenoma subtypes. Am. J. Surg. Pathol. 36, 1691-1699 (2012).

55. Fonseca S, Hoton D, Dardenne S et al. Histological and immunohistochemical revision of hepatocellular adenomas: a learning experience. Int. J. Hepatol. 2013, 398308 (2013).

56. van Aalten SM, Verheij J, Terkivatan T, Dwarkasing RS, de Man RA, Ijzermans JN. Validation of a liver adenoma classification system in a tertiary referral centre: implications for clinical practice. J. Hepatol. 55, 120-125 (2011).

57. Pan J, Chen L, Fan J et al. Retrospective study of hepatocellular adenomas based on the phenotypic classification system: a report from China. Histol. Histopathol. 29, 243-249 (2014).

58. Bellamy CO, Maxwell RS, Prost S, Azodo IA, Powell JJ, Manning JR. The value of immunophenotyping hepatocellular adenomas: consecutive resections at one UK centre. Histopathology 62, 431-445 (2013).

59. Sasaki M, Yoneda N, Kitamura S, Sato Y, Nakanuma Y. Characterization of hepatocellular adenoma based on the phenotypic classification: the Kanazawa experience. Hepatol. Res. 41, 982-988 (2011).

60. Laurent A, Dokmak S, Nault JC et al. European experience of 573 liver resections for hepatocellular adenoma: a cross-sectional study by the AFC-HCA-2013 study group. HPB (Oxford) 18, 748-755 (2016).

61. van Aalten SM, Witjes CD, de Man RA, Ijzermans JN, Terkivatan T. Can a decision-making model be justified in the management of hepatocellular adenoma? Liver Int. 32, 28-37 (2012).

62. de'Angelis N, Memeo R, Calderaro J et al. Open and laparoscopic resection of hepatocellular adenoma: trends over 23 years at a specialist hepatobiliary unit. $H P B$ (Oxford) 16, 783-788 (2014).

63. van Vledder MG, van Aalten SM, Terkivatan T, de Man RA, Leertouwer T, Ijzermans JN. Safety and efficacy of radiofrequency ablation for hepatocellular adenoma. J. Vasc. Interv. Radiol. 22, 787-793 (2011).

64. van der Sluis FJ, Bosch JL, Terkivatan T, de Man RA, Ijzermans JN, Hunink MG. Hepatocellular adenoma: cost-effectiveness of different treatment strategies. Radiology 252, 737-746 (2009).

65. Klompenhouwer AJ, Broker MEE, Thomeer MGJ, Gaspersz MP, de Man RA, IJzermans JNM. Retrospective study on timing of resection of hepatocellular adenoma. Br. J. Surg. 104, 1695-1703 (2017). 
66. Van der Borght S, Libbrecht L, Katoonizadeh A et al. Nuclear beta-catenin staining and absence of steatosis are indicators of hepatocellular adenomas with an increased risk of malignancy. Histopathology 51, 855-856 (2007).

67. Chiche L, David A, Adam R et al. Liver transplantation for adenomatosis: European experience. Liver Transpl. 22, 516-526 (2016).

68. Poussin K, Pilati C, Couchy G et al. Biochemical and functional analyses of gp130 mutants unveil JAK1 as a novel therapeutic target in human inflammatory hepatocellular adenoma. Oncoimmunology 2, e27090 (2013). 
